\title{
A COMPARATIVE STUDY OF LEVOBUPIVACAINE 0.5\% AND BUPIVACAINE 0.5\% IN EPIDURAL ANAESTHESIA IN ELECTIVE LOWER LIMB SURGERIES IN ADULTS
}

\author{
Vijayanand Siddalingappa ${ }^{1}$, Manisha Mohan Shivamoggi ${ }^{2}$ \\ ${ }^{1}$ Senior Associate Professor, Department of Anaesthesia, KIMS, Bangalore. \\ ${ }^{2}$ Registrar, Kovai Medical Centre, Coimbatore.
}

ABSTRACT
BACKGROUND
Bupivacaine produces fatal cardiotoxic and neurotoxic effects following accidental intravascular injection due to its $\mathrm{R}(+)$
enantiomer. Levobupivacaine, the pure $\mathrm{S}(-)$ enantiomer of bupivacaine, is found to be less toxic than its racemic parent and might
be a safer alternative.
The aim of this study was to compare the efficacy of Levobupivacaine $0.5 \%$ and Bupivacaine $0.5 \%$ in epidural anaesthesia in
elective lower limb surgeries in adults with respect to onset and maximum dermatomal level of sensory blockade, duration of
analgesia, onset, intensity and duration of motor blockade, haemodynamic parameters and perioperative complications.
Settings and Design- A prospective, randomised, comparative study.

\section{MATERIALS AND METHODS}

A study was conducted on 60 ASA I-II patients, aged 18 - 60 years of either sex posted for elective lower limb surgeries after ethical clearance and patient's written informed consent. The patients were assigned randomly (using computer generated randomisation) to receive epidurally either $12 \mathrm{~mL}$ of bupivacaine $0.5 \%$ as Group $\mathrm{B}(\mathrm{n}=30)$ or to receive $12 \mathrm{~mL}$ of levobupivacaine $0.5 \%$ as Group L $(n=30)$. Onset and maximum dermatomal level of sensory blockade, duration of analgesia, onset, intensity and duration of motor blockade and haemodynamic parameters were assessed. Perioperative complications were identified and treated accordingly. Study concluded when the patient first complained of pain.

Statistical Analysis- The study was analysed by Chi-square and student's ' $\mathrm{t}$ ' tests $(\mathrm{p}<0.05$ : statistically significant) and by using SPSS (Ver. 10.0.5) package.

\section{RESULTS}

The time of onset of motor blockade was prolonged in Group L when compared to Group B (B- $16.50 \pm 2.921 \mathrm{~min}$ and L- $19.60 \pm$ 4.889 min; $\mathrm{p}=0.004$ ). The intensity of motor blockade was greater in Group B when compared to Group L (B- $2.17 \pm 0.379$ and L$1.93 \pm 0.450 ; p=0.034$ ). No statistically significant difference was noted in terms of onset and maximum dermatomal level of sensory blockade, duration of analgesia, duration of motor blockade, haemodynamic parameters and perioperative complications between both the groups.

\section{CONCLUSION}

Levobupivacaine $0.5 \%$ could prove to be a good alternative, as it produces a sensory blockade, haemodynamic and side effect profile equivalent to Bupivacaine $0.5 \%$ in lower limb surgeries. In terms of motor blockade, the onset is delayed and is less dense with levobupivacaine as compared to bupivacaine but with a similar duration.

\section{KEYWORDS}

Epidural Anaesthesia; Bupivacaine; Levobupivacaine; Lower Limb Surgeries; Clinical Efficacy.

HOW TO CITE THIS ARTICLE: Siddalingappa V, Shivamoggi MM. A comparative study of levobupivacaine $0.5 \%$ and bupivacaine 0.5\% in epidural anaesthesia in elective lower limb surgeries in adults. J. Evolution Med. Dent. Sci. 2017;6(50):3822-3827, DOI: $10.14260 /$ Jemds/2017/826

\section{BACKGROUND}

Epidural anaesthesia is a versatile regional anaesthetic technique widely used in practice, which over spinal anaesthesia has the advantages such as it provides effective surgical anaesthesia which can be prolonged with postoperative

Financial or Other, Competing Interest: None.

Submission 01-06-2017, Peer Review 15-06-2017,

Acceptance 17-06-2017, Published 22-06-2017.

Corresponding Author:

Dr. Manisha Mohan Shivamoggi,

C/o. Dr. Vivekanand Kulkarni,

11/12, Shivleelamrut Bungalow,

Behind Ganharava Palace Apartment,

Kasbekar Park, New Palace Road,

Kolhapur-416003, Maharashtra.

E-mail: shivamoggimanu@gmail.com

DOI: $10.14260 /$ jemds $/ 2017 / 826$ stability.1,2 Different local anaesthetics are used for epidural anaesthesia namely lignocaine, bupivacaine, ropivacaine and now levobupivacaine.

Bupivacaine is a long-acting local anaesthetic, which shows good motor/sensory separation. ${ }^{3}$ It has a chiral centre in its structure and hence exhibits stereoisomerism. It is available in a commercial preparation as a racemic mixture (50:50) of its two enantiomers, levobupivacaine $S(-)$ isomer and dextrobupivacaine $\mathrm{R}(+)$ isomer. While these two molecules have identical physicochemical properties, they have distinct pharmacological and toxicological effects. ${ }^{4}$ Although, bupivacaine has been safely used in regional anaesthesia for many years, fatal cardiotoxic and neurotoxic effects which have been linked to its R (+) isomer may be seen following its accidental intravascular injection. Therefore, pure S (-) enantiomers of bupivacaine, i.e. ropivacaine and levobupivacaine with fewer toxic effects 
were thus introduced into clinical anaesthesia practice. ${ }^{5-7}$

Levobupivacaine has emerged in recent years as a safer alternative for regional anaesthesia than its racemic parent. The affinity of the $\mathrm{S}(-)$ isomer to the cardiac sodium channel in the inactive state is lower than that of the $\mathrm{R}(+)$ isomer of bupivacaine. Reports of its cardiotoxicity and neurotoxicity are scarce. The occasional toxic symptoms with its use are usually reversible with minimal treatment with no fatal outcome. Hence, levobupivacaine has a potentially greater margin of safety than racemic bupivacaine and can prove to be a better alternative to bupivacaine. . $^{8-13}$

Hence, this study is undertaken to compare the effectiveness of Levobupivacaine $0.5 \%$ with Bupivacaine $0.5 \%$ for epidural anaesthesia in elective lower limb surgeries.

\section{MATERIALS AND METHODS \\ Source of Data}

The present study titled "A comparative study of levobupivacaine $0.5 \%$ and bupivacaine $0.5 \%$ in epidural anaesthesia in elective lower limb surgeries in adults" was conducted in the Department of Anaesthesiology and Critical Care, Kempegowda Institute of Medical Sciences and Research Centre, Bengaluru from December 2013 to July 2015.

\section{Type of Study}

A prospective, randomised, comparative study.

\section{Power Analysis}

A post-hoc power analysis was carried out using PASS-11 Software. ${ }^{14}$ The mean time of onset of motor blockade in Group B was $16.50 \pm 2.921 \mathrm{~min}$ and that in Group L was 19.60 $\pm 4.889 \mathrm{~min}$. The Group sample sizes of 30 and 30 achieve $85 \%$ power to detect a difference of -3.10 between the groups with a significance level (alpha) of 0.05 using a two-sided two-sample t-test.

\section{Sampling Method}

Patients were randomised to treatment group using computer generated randomisation.

\section{Statistical Analysis}

The study was analysed by Chi-square and student's ' $t$ ' tests ( $p<0.05$ : statistically significant). Data was entered in Microsoft Excel and analysed using SPSS (Statistical Package for Social Science, Ver. 10.0.5) package.

\section{Method of Collection of Data}

After ethical clearance and written informed consent from the patients a prospective, randomised, comparative study was conducted in 60 patients of ASA Grade 1 and 2 aged between 18 to 60 years of either sex posted for elective lower limb surgeries.

\section{Inclusion Criteria}

Patients with an age group of 18 to 60 years of either sex, ASA Grades 1 and 2, patients posted for elective lower limb surgeries, patients with height between $150-180 \mathrm{~cm}$ and weight between $50-80 \mathrm{~kg}$.

\section{Exclusion Criteria}

Patient's refusal for regional anaesthesia, known allergy to local anaesthetics, pregnant and lactating women, morbidly obese patients and patients having the following: Local infection, severe hypovolaemia, bleeding diathesis and coagulopathy, uncontrolled hypertension and diabetes mellitus, neurological disorders, raised intracranial tension, deformities of spine and hepatic diseases.

The study population was thus selected based on the above criteria and then randomly divided into two groups of 30 patients in each group based on the study drug given as follows-

1. Group L $(\mathrm{n}=30)-12 \mathrm{~mL}$ of levobupivacaine $0.5 \%$ epidurally.

2. Group $B(n=30)-12 \mathrm{~mL}$ of bupivacaine $0.5 \%$ epidurally.

\section{Procedure}

Preoperative assessment was done for each patient and written informed consent was taken. Patients were fasted for at least 8 hours before the procedure. On the day of surgery, intravenous line was secured with 18-G cannula in upper limb. Patients were monitored using automated multiparameter monitor. Basal vital parameters like heart rate, blood pressure, respiratory rate and SPO2 were noted.

Patients were placed in a lateral position. Under strict asepsis, the skin at the L2-L3/L3-L4 level was infiltrated with $2 \mathrm{~mL}$ of Inj. Lignocaine 2\%. Epidural space was identified with loss of resistance to air technique at the desired level using 18-G Tuohy's needle. An epidural catheter was advanced in cephalad direction into epidural space for $3 \mathrm{~cm}$ and fixed. Test dose of $3 \mathrm{~mL}$ of Inj. Lignocaine $2 \%$ with Adrenaline 1:200000 was given after negative aspiration for CSF and blood. This was to exclude the presence of needle in the subarachnoid space and epidural vessels. After confirming the correct position of the catheter, patient was turned to supine position. Five minutes after the test dose when there was no evidence of subarachnoid or intravascular injection, $12 \mathrm{~mL}$ of study drug was given at a rate of $1 \mathrm{~mL} / 3$ secs through the catheter.

\section{Intraoperatively, the following Parameters were Monitored}

- Onset of sensory blockade.

- Maximum dermatomal level of sensory blockade.

- Duration of analgesia.

- Onset of motor blockade.

- Maximum intensity of motor blockade (using Modified Bromage scale).

- Duration of motor blockade.

- Haemodynamic changes-Sp02, heart rate, systolic blood pressure, diastolic blood pressure and mean blood pressure. All the parameters were recorded every minute for the first 5 minutes, every 5 minutes till the end of 1 hour and then every 15 minutes till the end of surgery.

- Intraoperative and postoperative complications if anysuch as nausea, vomiting, hypotension, bradycardia and respiratory depression was looked for, recorded and treated accordingly.

After the surgery, patients were referred to the post anaesthesia care unit where they stayed until there was 
complete recovery of sensory and motor blockade. Postoperatively, vital parameters were recorded every 15 minutes. Duration of analgesia, duration of motor blockade and any adverse events were noted. Study concluded when the patient first complained of pain after the administration of the drug under study epidurally. Continuous epidural infusion was given as Inj. Bupivacaine $0.125 \%$ with $1 \mu \mathrm{g}$ of Inj. Fentanyl in each $\mathrm{mL}$ of local anaesthetic for the next 72 hours postoperatively.

\section{Definitions}

\section{Onset of Sensory Blockade}

It is the time taken from the completion of the injection of study drug till the patient does not feel the pinprick at L1 level.

\section{Maximum Dermatomal Level of Sensory Blockade}

It is defined as the highest dermatomal level, at which the patient does not feel the pinprick after completion of the injection of the study drug.

\section{Duration of Analgesia}

It is taken from the time of injection of the study drug till the patient complains of pain at the site of surgery.

\section{Onset of Motor Blockade}

It is taken from the completion of the injection of study drug till the patient develops Modified Bromage Scale Grade 1.

\section{Maximum Intensity of Motor Blockade}

It is defined as the maximum intensity of motor blockade attained after completion of the injection of the study drug.

\section{Duration of Motor Blockade}

It is taken from the time of injection of the study drug till the patient develops Modified Bromage Scale Grade 0.

\section{Hypotension}

It was defined as reduction of systolic blood pressure more than $30 \%$ below baseline value or mean blood pressure less than $90 \mathrm{mmHg}$. Hypotension was treated with Inj. Ephedrine $6 \mathrm{mg}$ IV in bolus doses and increased administration of intravenous fluids.

\section{Bradycardia}

It was defined as heart rate less than $50 /$ minute and was treated with Inj. Atropine $0.6 \mathrm{mg}$ IV.

\section{Modified Bromage Scale: ${ }^{15}$}

- 0 : No motor block.

- 1 : Inability to raise extended leg; able to move knees and feet.

- $\quad 2$ : Inability to raise extended leg and move knee; able to move feet.

- 3: Complete block of motor limb.

\section{RESULTS}

In the present study, we found that both the study groups were comparable with respect to age, height, weight (Table 1), gender, ASA grade (Table 2) and duration of surgery (Table 3).
The mean time of onset of sensory blockade in Group B was $11.43 \pm 2.431 \mathrm{~min}$ and that in Group L was $12.37 \pm 2.157$ min. Hence, with a ' $p$ ' value of 0.121 there was no statistically significant difference between both the groups in this regard (Table 4).

The mean time of onset of motor blockade in Group B was $16.50 \pm 2.921 \mathrm{~min}$ and that in Group L was $19.60 \pm 4.889 \mathrm{~min}$. Hence, with a ' $p$ ' value of 0.004 ( $p<0.05$ is significant), there was a statistically significant difference between both the groups in this regard. That is the onset of motor blockade was faster with bupivacaine when compared to levobupivacaine (Table 4).

Among patients in Group B 13.3\% attained a level of T8, T9 and T12 each, 36.7\% attained a level of T10 and 23.3\% attained a level of T11. Among patients in Group L 20\% attained a level of T8, $6.7 \%$ a level of T9, 33.3\% a level of T10, $13.3 \%$ a level of $\mathrm{T} 11$ and $26.7 \%$ a level of T12. There was no significant difference in the maximum dermatomal level of sensory blockade achieved in both the groups, as indicated by 'p' value of 0.514 (Table 4).

In Group B there were 25 patients (83.3\%) with Grade 2 motor block and 5 patients $(16.7 \%)$ with Grade 3 and none with Grades 0 and 1. In Group L 4 patients (13.3\%) had Grade 1 block, 24 patients (80\%) had Grade 2 block, 2 patients $(0.07 \%)$ had Grade 3 and none had Grade 0. The mean maximum intensity of motor blockade in Group B was $2.17 \pm$ 0.379 and that in Group L was $1.93 \pm 0.450$. Hence, with a 'p' value of 0.034 ( $\mathrm{p}<0.05$ is significant), there was a statistically significant difference between both the groups in this regard. That is bupivacaine group achieved a greater intensity of motor blockade when compared to the levobupivacaine group (Table 4).

The mean duration of analgesia in Group B was $195.17 \pm$ $22.685 \mathrm{~min}$ and that in Group L was $194.50 \pm 21.907 \mathrm{~min}$. Hence, there is no significant difference between both the groups in this regard as indicated by a 'p' value of 0.908 (Table 4).

The mean duration of motor blockade in Group B was $174.83 \pm 22.302$ min and that in Group L was $174.00 \pm 20.146$ min. Hence, there is no significant difference between both the groups with respect to the duration of motor blockade as indicated by a ' $p$ ' value of 0.880 (Table 4).

There was no significant difference between bupivacaine and levobupivacaine groups with respect to SpO2, HR, SBP, DBP and MBP recorded at timed intervals and with respect to perioperative complications (Table 5).

\begin{tabular}{|c|c|c|c|c|}
\hline \multicolumn{2}{|c|}{ Variables } & Group B & Group L & P value \\
\hline $\begin{array}{c}\text { Age } \\
\text { (in years) }\end{array}$ & Mean \pm SD & $38.3 \pm 13.370$ & $38.3 \pm 13.603$ & 1.000 \\
\hline $\begin{array}{c}\text { Height (in } \\
\text { cm) }\end{array}$ & Mean \pm SD & $\begin{array}{c}167.2 \pm \\
6.420\end{array}$ & $\begin{array}{c}166.9 \pm \\
5.996\end{array}$ & 0.836 \\
\hline $\begin{array}{c}\text { Weight } \\
\text { (in kg) }\end{array}$ & Mean \pm SD & $67.3 \pm 5.388$ & $66.5 \pm 5.463$ & 0.586 \\
\hline \multicolumn{4}{|c|}{ Table 1. Comparison of Demographic Data between the } \\
Study Groups \\
\hline
\end{tabular}




\begin{tabular}{|c|c|c|c|c|c|c|c|}
\hline \multirow{2}{*}{ Variables } & & \multicolumn{2}{|c|}{ Group B } & \multicolumn{2}{|c|}{ Group L } & \multirow{2}{*}{$\mathrm{X}^{2}$} & \multirow{2}{*}{$P$ value } \\
\hline & & No & $\%$ & No & $\%$ & & \\
\hline \multirow{3}{*}{ Gender } & Male & 21 & 70.0 & 23 & 76.7 & \multirow{3}{*}{0.341} & \multirow{3}{*}{0.559} \\
\hline & Female & 9 & 30.0 & 7 & 23.3 & & \\
\hline & Total & 30 & 100 & 30 & 100 & & \\
\hline \multirow{3}{*}{$\begin{array}{c}\text { ASA } \\
\text { Grade }\end{array}$} & $\begin{array}{c}\text { Grade } \\
1\end{array}$ & 22 & 73.3 & 19 & 63.3 & \multirow{3}{*}{0.693} & \multirow{3}{*}{0.405} \\
\hline & \begin{tabular}{c|} 
Grade \\
2
\end{tabular} & 8 & 26.7 & 11 & 36.7 & & \\
\hline & Total & 30 & 100 & 30 & 100 & & \\
\hline \multicolumn{8}{|c|}{$\begin{array}{c}\text { Table 2. Distribution of Gender and ASA Grade } \\
\text { in the Study Groups }\end{array}$} \\
\hline
\end{tabular}

\begin{tabular}{|c|c|c|}
\hline & $\begin{array}{c}\text { Group B } \\
\text { Mean } \pm \text { SD }\end{array}$ & $\begin{array}{c}\text { Group L } \\
\text { Mean } \pm \text { SD }\end{array}$ \\
\hline $\begin{array}{c}\text { Duration of } \\
\text { Surgery (min) }\end{array}$ & $178.67 \pm 33.834$ & $174.83 \pm 38.807$ \\
\hline ' $\mathrm{t}$ ' value & 0.166 \\
\hline 'p' value & 0.685 \\
\hline \multicolumn{2}{|c|}{ Table 3. Mean Values of Duration of Surgery in the Study } \\
Groups \\
\hline
\end{tabular}

\begin{tabular}{|c|c|c|c|}
\hline $\begin{array}{c}\text { Study } \\
\text { Variables }\end{array}$ & $\begin{array}{c}\text { Group B } \\
\text { (Mean } \pm \text { SD) }\end{array}$ & $\begin{array}{c}\text { Group L } \\
\text { (Mean } \pm \text { SD) }\end{array}$ & P value \\
\hline $\begin{array}{c}\text { Onset of Sensory } \\
\text { Blockade (min) }\end{array}$ & $11.43 \pm 2.431$ & $12.37 \pm 2.157$ & 0.121 \\
\hline $\begin{array}{c}\text { Onset of Motor } \\
\text { Blockade (min) }\end{array}$ & $16.50 \pm 2.921$ & $19.60 \pm 4.889$ & 0.004 \\
\hline $\begin{array}{c}\text { Maximum } \\
\text { Dermatomal Level } \\
\text { of Sensory Blockade }\end{array}$ & $\mathrm{T}_{8}-\mathrm{T}_{12}$ & $\mathrm{~T}_{8}-\mathrm{T}_{12}$ & 0.514 \\
\hline $\begin{array}{c}\text { Maximum Intensity } \\
\text { of Motor Blockade } \\
\text { (using Modified } \\
\text { Bromage Scale) }\end{array}$ & $2.17 \pm 0.379$ & $1.93 \pm 0.450$ & 0.034 \\
\hline $\begin{array}{c}\text { Duration of Sensory } \\
\text { Blockade (min) }\end{array}$ & $195.17 \pm 22.685$ & $194.50 \pm 21.907$ & 0.908 \\
\hline $\begin{array}{c}\text { Duration of Motor } \\
\text { Blockade (min) }\end{array}$ & $174.83 \pm 22.302$ & $174.00 \pm 20.146$ & 0.880 \\
\hline \multicolumn{3}{|c|}{ Table 4. Comparison of Characteristics of Block between } \\
\hline \multicolumn{2}{|c|}{ the Study Groups } \\
\hline
\end{tabular}

\begin{tabular}{|c|c|c|c|c|}
\hline \multirow{2}{*}{$\begin{array}{c}\text { Perioperative } \\
\text { Complication }\end{array}$} & \multicolumn{2}{|c|}{ Group B } & \multicolumn{2}{c|}{ Group L } \\
\cline { 2 - 5 } & No. & $\%$ & No. & $\%$ \\
\hline $\begin{array}{c}\text { Nausea/ } \\
\text { Vomiting }\end{array}$ & 4 & 13.3 & 2 & 6.7 \\
\hline Hypotension & 0 & 0 & 0 & 0 \\
\hline $\begin{array}{c}\text { No } \\
\text { Complication }\end{array}$ & 26 & 86.7 & 28 & 93.3 \\
\hline Total & 30 & 100 & 30 & 100 \\
\hline$X^{2}$ & \multicolumn{5}{|c|}{0.741} \\
\hline 'p' value & \multicolumn{4}{|c|}{0.389} \\
\hline Table 5. Comparison of Perioperative Complications \\
in the Study Groups \\
\hline
\end{tabular}

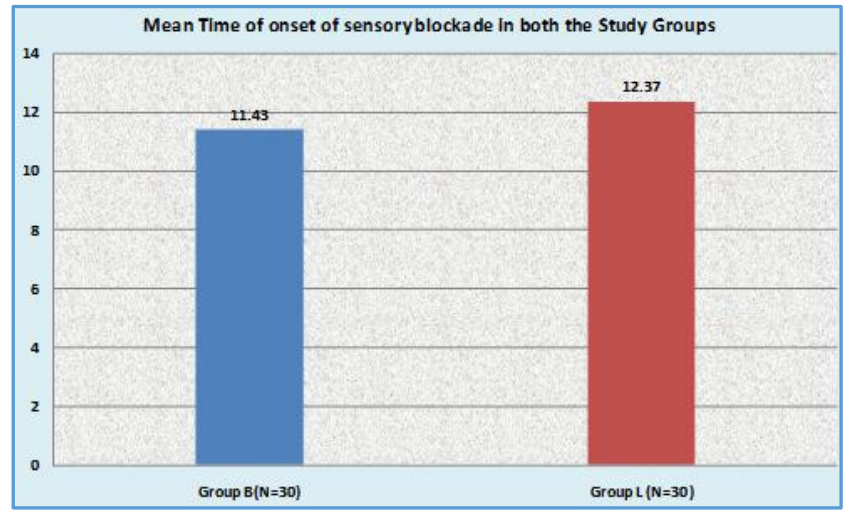

Graph 1. Comparison of Mean Values of Time of Onset of Sensory Blockade

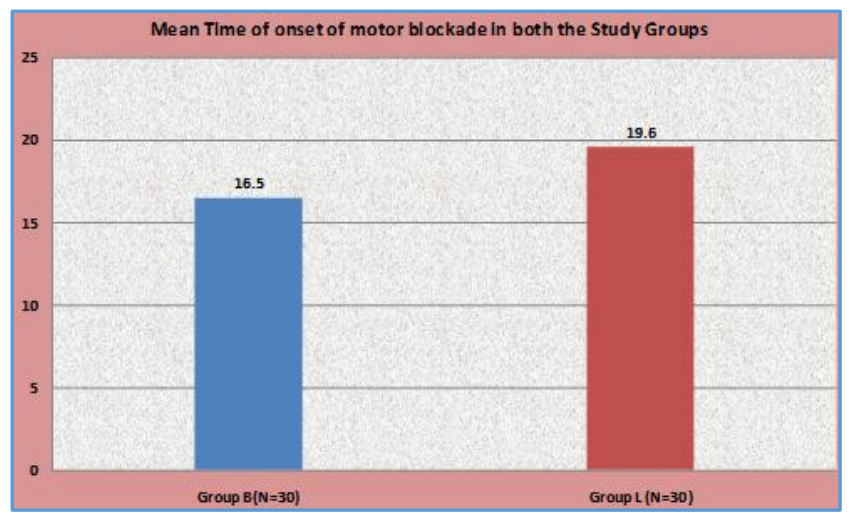

Graph 2. Comparison of Mean Values of Time of Onset of Motor Blockade

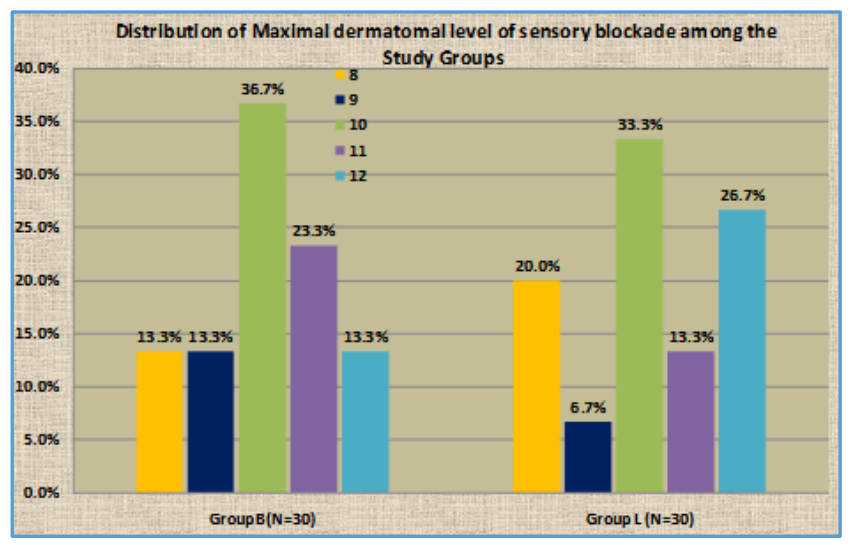

Graph 3. Comparison of Mean Values of Maximum Dermatomal Level of Sensory Blockade

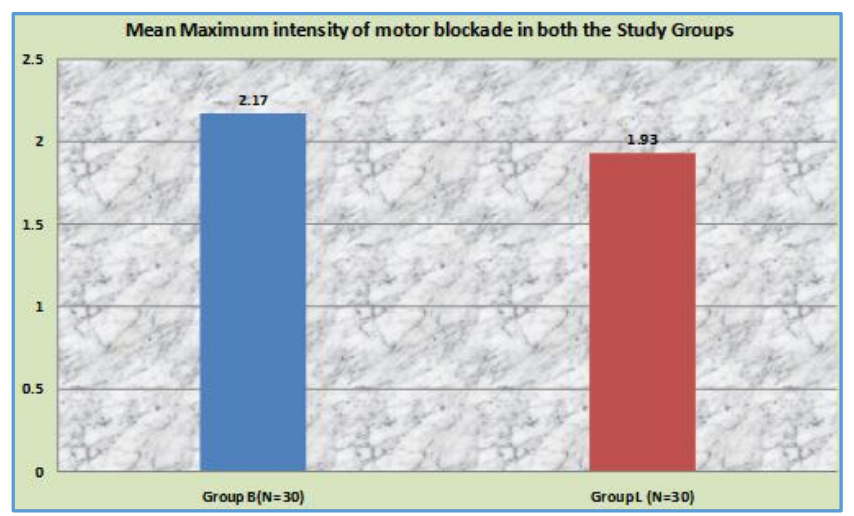

Graph 4. Comparison of Mean Values of Maximum Intensity of Motor Blockade 


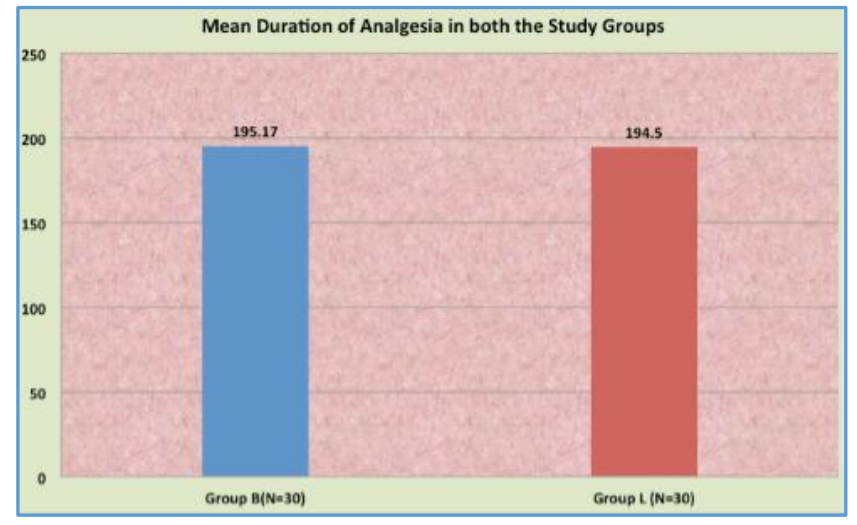

Graph 5. Comparison of Mean Values of Duration of Analgesia

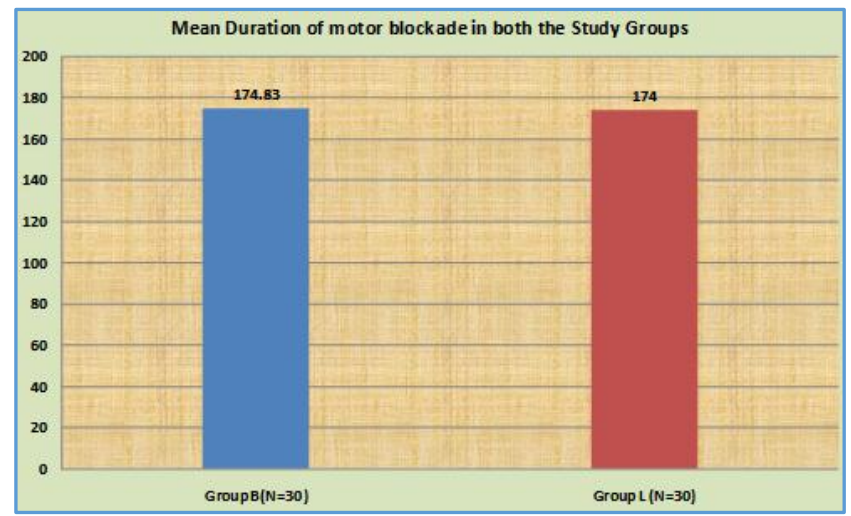

Graph 6. Comparison of Mean Values of Duration of Motor Blockade

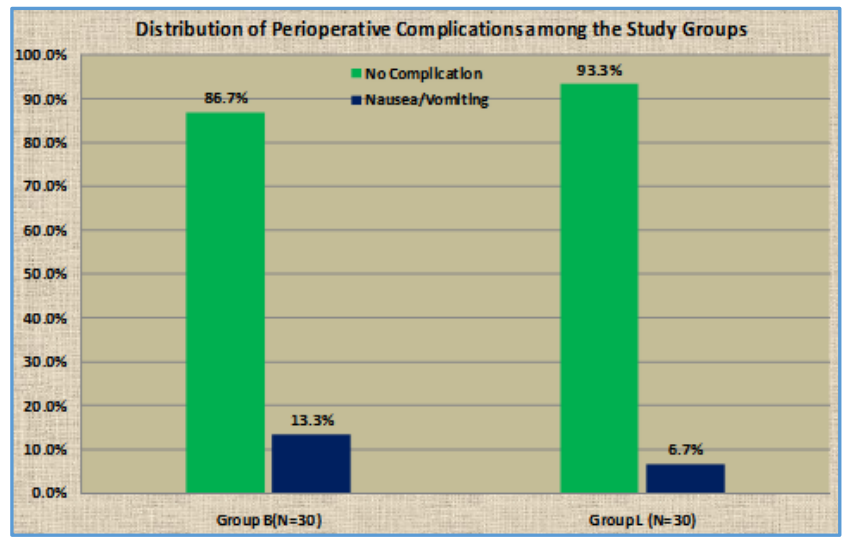

Graph 7. Comparison of Mean Values of Perioperative Complications

\section{DISCUSSION}

Bupivacaine produces fatal cardiotoxic and neurotoxic effects following accidental intravascular injection, which is attributed to its $\mathrm{R}(+)$ isomer, thus showing enantioselectivity in producing toxicity. Levobupivacaine a pure $\mathrm{S}(-)$ enantiomer of bupivacaine has been found to be less cardiotoxic and less neurotoxic in various preclinical studies when compared to bupivacaine. Hence, levobupivacaine has a safer pharmacological profile and has emerged as a safer alternative for regional anaesthesia than its racemic parent. ${ }^{3-9}$

The aim of this study was to compare the efficacy of levobupivacaine $0.5 \%$ and bupivacaine $0.5 \%$ in epidural anaesthesia in elective lower limb surgeries in adults with respect to onset and maximum dermatomal level of sensory blockade, duration of analgesia, onset, intensity and duration of motor blockade, haemodynamic parameters and perioperative complications.

The present study consisted of 60 patients aged between 18 - 60 years of either sex, ASA Grade 1 - 2 undergoing epidural anaesthesia for elective lower limb surgeries. The study population was divided into two groups of 30 each based on the study drug used in each group as:

- Group L ( $\mathrm{n}=30)-12 \mathrm{~mL}$ of isobaric levobupivacaine $0.5 \%$ epidurally.

- Group B ( $\mathrm{n}=30)-12 \mathrm{~mL}$ of isobaric bupivacaine $0.5 \%$ epidurally.

In the present study, both the groups were comparable with respect to age, height, weight, gender, ASA grade and duration of surgery.

Surav DB et al ${ }^{16}$ found that $10 \mathrm{~mL}$ of $0.5 \%$ levobupivacaine plus $5 \mathrm{~mL}$ of $0.9 \%$ saline produces a block clinically comparable to that of $10 \mathrm{~mL}$ of $0.75 \%$ levobupivacaine plus $5 \mathrm{~mL}$ of $0.9 \%$ saline for transurethral resection of prostate surgery. Hence, we have used $0.5 \%$ levobupivacaine in our study.

The study drug volume of $12 \mathrm{~mL}$ was calculated based on the amount of drug required per segment in the lumbar region. ${ }^{17}$

Fesih Kara et al, ${ }^{5}$ Kopacz et al, ${ }^{18}$ Cox CR et al ${ }^{19}$ and Casati $\mathrm{A}$ et $\mathrm{al}^{20}$ in their respective studies found that there was no significant difference between the bupivacaine and levobupivacaine groups with respect to time of onset of sensory blockade, which is similar to our study.

Kopacz et $\mathrm{al}^{18}$ found that the levobupivacaine group showed a significantly slower onset of motor blockade with only 4 out of 28 patients (14\%) having detectable blockade after 30 mins compared with 20 out of 28 patients $(71 \%)$ in the bupivacaine group. Hence, with a $\mathrm{p}<0.001$ there was significant difference between both the groups in this regard, which is similar to our study.

Cox CR et al'19 in 1998 in their study titled 'Extradural S (-)-bupivacaine: comparison with racemic RS-bupivacaine' found that the time of onset of motor blockade in bupivacaine (racemic RS-bupivacaine $0.5 \%$ ) group was $17.0 \pm 7.0 \mathrm{~min}$ and that in levobupivacaine (S (-)-bupivacaine $0.5 \%$ ) group was $25.0 \pm 23.0 \mathrm{~min}$. Hence, there was a significant difference between both the groups in this regard with bupivacaine producing a faster onset of motor blockade than levobupivacaine, which is similar to our study.

Kopacz et al, ${ }^{18}$ Cox CR et al, ${ }^{19}$ Casati A et al ${ }^{20}$ and Pedro Paulo Tanaka TSA et $\mathrm{al}^{21}$ in their respective studies found that there was no significant difference between bupivacaine and levobupivacaine with respect to the maximum dermatomal level of sensory blockade achieved, which is similar to our study. The peak block height was between T5 and $\mathrm{T} 6$ in both treatment groups.

Cox CR et $\mathrm{al}^{19}$ found that in the S (-) bupivacaine $0.5 \%$ (levobupivacaine) group, 14 out of 29 patients did not develop motor blockade. This is in accordance with our study where levobupivacaine group achieved a lesser intensity of motor blockade when compared to bupivacaine group.

Kopacz et al ${ }^{18}$ found that in levobupivacaine group, only 4 out of 28 patients $(14 \%)$ had detectable blockade after 30 mins compared with 20 out of 28 patients (71\%) in the bupivacaine group $(\mathrm{p}<0.001)$. This is in accordance with our 
study, where levobupivacaine group attained a lesser intensity of motor blockade when compared to bupivacaine group.

Casati A et al ${ }^{20}$ found that complete motor block (modified Bromage score $\geq 2$ ) was observed in all patients of bupivacaine group (100\%) and 12 patients of Levobupivacaine group (80\%), which is in accordance with our study where levobupivacaine group attained a lesser intensity of motor blockade when compared to bupivacaine group.

Pedro Paulo Tanaka TSA et al ${ }^{21}$ found that there was statistically significant difference in Modified Bromage level 2 blockade in racemic bupivacaine group as compared to the levobupivacaine group, which is similar to our study.

Fesih Kara et al, ${ }^{5}$ Kopacz et al, ${ }^{18}$ Cox CR et al ${ }^{19}$ and Casati $A$ et $\mathrm{al}^{20}$ in their respective studies found that there was no significant difference between the bupivacaine and levobupivacaine groups with respect to duration of analgesia and duration of motor blockade, which is similar to our study.

In the present study, we found that there was no significant difference between both the groups with respect to SpO2, HR, SBP, DBP, MBP and perioperative complications which is in accordance with studies done by Fesih Kara et al, 5 Kopacz et al, ${ }^{18} \mathrm{Cox} \mathrm{CR}$ et al ${ }^{19}$ and Casati A et al. ${ }^{20}$

\section{CONCLUSION}

Based on the present clinical comparative study, we conclude that Levobupivacaine $0.5 \%$, when administered through epidural route provides adequate anaesthesia for elective lower limb surgeries comparable to Bupivacaine $0.5 \%$ at equal doses. Levobupivacaine achieves a sensory blockadeonset, maximum dermatomal level attained and duration of analgesia comparable to bupivacaine. The duration of motor blockade, haemodynamic parameters and perioperative complications were similar between the two drugs. However, slower onset and lesser intensity of motor blockade were observed with levobupivacaine when compared to bupivacaine.

Hence, we conclude that Levobupivacaine $0.5 \%$ can be used as a safer alternative to Bupivacaine $0.5 \%$ for epidural anaesthesia in lower limb surgeries.

\section{REFERENCES}

[1] Bridenbaugh PO, Greene NM. Spinal (Subarachnoid) Neural Blockade. In: Cousins MJ, Bridenbaugh PO, eds. Neural blockade in clinical anesthesia and management of pain. $2^{\text {nd }}$ edn. Philadelphia: Lippincott Williams and Wilkins 1988; p. 248.

[2] Collins VJ. Principles of anesthesiology general and regional anesthesia. $3^{\text {rd }}$ edn. Philadelphia: Lea Febiger 1993:1571-98.

[3] McLeod GA, Burke D. Levobupivacaine. Anesthesia 2001;56(4):331-41.

[4] Bajwa SJS, Kaur J. Clinical profile of levobupivacaine in regional anesthesia: a systematic review. J Anaesthesiol Clin Pharmacol 2013;29(4):530-9.

[5] Kara F, Kursad H, Celik M, et al. Comparison of the effects of epidural $0.5 \%$ bupivacaine and $0.5 \%$ levobupivacaine administration on anesthesia quality, side effect incidence, and analgesia requirement times in hip and low extremity surgery. Turk J Med Sci 2013;43(4):580-5.
[6] Jacob AK, Kopp SL, Bacon DR, et al. The history of anesthesia. In: Barash PG, Cullen BF, Stoelting RK, et al. eds. Clinical anesthesia. $6^{\text {th }}$ edn. Philadelphia: Lippincott Williams \& Wilkins 2009; p. 15.

[7] Albright GA. Cardiac arrest following regional anesthesia with etidocaine or bupivacaine. Anesthesiology 1979;51(4):285-7.

[8] Burlacu CL, Buggy DJ. Update on local anesthetics: focus on levobupivacaine. Ther Clin Risk Manag 2008;4(2):381-92.

[9] Bardsley H, Gristwood R, Baker H, et al. A comparison of the cardiovascular effects of levobupivacaine and rac-bupivacaine following intravenous administration to healthy volunteers. $\mathrm{Br} \mathrm{J}$ Clin Pharmacol 1998;46(3):245-9.

[10] Koch T, Fichtner A, Schwemmer U, et al. Levobupivacaine for epidural anesthesia and postoperative analgesia in hip surgery. Der Anesthetist 2008;57(5):475-82.

[11] Foster RH, Markham A. Levobupivacaine: a review of its pharmacology and use as a local anesthetic. Drugs 2000;59(3):531-79.

[12] Gennery B, Mather LE, Strichartz G. Levobupivacaine: new preclinical and clinical data. J Critical Care 2000;19(2):132-48.

[13] Leone S, Di Cianni S, Casati A, et al. Pharmacology, toxicology and clinical use of new long acting local anesthetics, ropivacaine and levobupivacaine. Acta Biomed 2008;79(2):92-105.

[14] Hintze J. PASS 11. NCSS, LLC. Kaysville, Utah, USA. 2011. http://www.ncss.com.

[15] Brull R, Macfarlane AJR, Chan VWS. Spinal, Epidural, and caudal anesthesia. In: Miller RD. edr. Miller's Anesthesia. $8^{\text {th }}$ edn. Philadelphia: Saunders Elsevier 2015; p. 1703.

[16] Surav DB, Hanci A, Sivrikaya GU, et al. The effects of different concentrations and equivalent volumes of levobupivacaine in epidural anesthesia. Current Therapeutic Research Clin Exp 2011;72(2):71-8.

[17] Collins VJ. Principles of anesthesiology general and regional anesthesia. $3^{\text {rd }}$ edn. Philadelphia: Lea Febiger 1993:1578-82.

[18] Kopacz DJ, Allen HW, Thompson GE. A comparison of epidural levobupivacaine $0.75 \%$ with racemic bupivacaine for lower abdominal surgery. Anesth Analg 2000;90(3):642-8.

[19] Cox CR, Faccenda KA, Gilhooly C, et al. Extradural S(-)-bupivacaine: comparison with racemic RS-bupivacaine. Br J Anaesth 1998;80(3):289-93.

[20] Casati A, Santorsola R, Aldegheri G, et al. Intraoperative epidural anesthesia and postoperative analgesia with levobupivacaine for major orthopedic surgery: a double-blind, randomized comparison of racemic bupivacaine and ropivacaine. J Clin Anesth 2003;15(2):126-31.

[21] Tanaka PP, Ogleari $M$, Valmorbida $P$, et al. Levobupivacaine $0.5 \%, 50 \%$ enantiomeric excess bupivacaine and racemic bupivacaine in epidural anesthesia for lower abdominal procedures. Comparative study. Rev Bras anestesiol 2005;55(6):597-605. 